from its own resources, independently of the United States. But this requires a nuclear deterrent force or forces controlled by West Europeans themselves, for which the British and French nuclear forces now provide a basis, as is today increasingly recognized elsewhere in Western Europe (the West German government, for example, has officially welcomed the British decision to deploy Trident). And in the short run there can be no balance in Europe without the commitment of American nuclear forces, for which some price will have to be paid and some risks accepted.

Hedley Bull is Montague Burton Professor of International Relations at Oxford University, and was formerly a Director of the Arms Control and Disarmament Research Unit in the British Foreign Office.

\title{
Environmental chemistry: a mixed reaction
}

\section{Peter S. Liss}

The Handbook of Environmental Chemistry. Edited by O. Hutzinger. Three volumes of two parts. Vol.1A The Natural Environment and the Biogeochemical Cycles pp.258, ISBN 3-540-09688-4. Vol.2A Reactions and Processes pp.307, ISBN 3-540-09689-2. Vol. 3A Anthropogenic Compounds pp.274, ISBN 3-540-09690-6. (Springer-Verlag: 1980.) Vol.1A DM98, \$57.70; Vol.2A DM 126, \$74.40; Vol.3A DM98, \$57.70.

THESE three volumes are the first part of what we are told in the preface will be a multi-part venture. Part Bs for all the present volumes are promised shortly, with further parts to be published at some later date. Readers are even asked for their suggestions as to what future books might contain! Thus we appear to be at the start of what could become a major exercise in environmental chemistry publishing. At this early stage perhaps it is timely to examine both the achievements of what is now published and see what guidance it gives for future projects of this sort.

Each of the present volumes contains between nine and thirteen chapters, each by different authors. Generally they seem to be aimed at an audience at post-graduate level. The whole is edited by $\mathrm{O}$. Hutzinger who is in the Laboratory of Environmental and Toxicological Chemistry at the University of Amsterdam. He has clearly put in an enormous amount of work to get the venture started and presumably continues to labour mightily on future volumes. Although editorial supervision is obviously important for a worthwhile outcome, the editor is, as always in a project of this kind, almost totally at the mercy of the people who are writing the individual articles. In spite of the fact that the authors are generally well known in their subject areas, the final result here is a series of chapters of very uneven content and quality. Some authors have done a really excellent job in summarizing their allotted topics; conversely, several chapters appear to do considerable injustice to the sub-branch of environmental chemistry which they are supposed to cover. This patchiness seriously limits the value of the whole venture. Presumably, the whole purpose of a handbook is that it can always be relied on to give the sort of information and understanding one requires. If this reliability is lost by some contributions being sub-standard, then one might as well go back to using a collection of textbooks and journal articles covering more restricted parts of the topic.

Since only Part As are currently available, it is not possible to comment at this stage on the comprehensiveness of the Handbook or on problems of overlap or underlap between chapters. The arrangement into three volumes is done in a rather interesting way. Volume 1 contains chapters on the hydrosphere, atmosphere, oceans and soils as well as contributions on aspects of biogeochemical cycling. In this last group the article by P. J. Craig, "Metal Cycles and Biological Methylation', deserves special mention since it is a most informative and well balanced appraisal of the topic, particularly with respect to the routes and importance of methylation reactions.

The second volume is concerned with reactions and processes which transport and modify substances in the environment.

Volume 3 contains nine chapters, each on a particular man-made chemical (or group of chemicals) or natural substance whose behaviour is being affected by anthropogenic activities. The list of chemicals covered so far is plainly far from complete. This treatment by individual substance is perhaps how one might have expected the whole Handbook to have been organized. The editor is surely right in adopting the approach of establishing the basic principles of the subject in Vols 1 and 2 before proceeding to a detailed examination of individual chemicals.

As to the future of the Handbook the message is clear - vigilance in choice of authors is paramount. Although articles must obviously be written by experts in their subject area, it is more important that they should be prepared to make the effort to do justice to their topic rather than be well known in the field.

Peter S. Liss is Reader in the School of Environmental Sciences, University of East Anglia, and Scientific Adviser in the Environmental Studies Section at CEGB Headquarters.

\section{Immunity in fertility}

\section{W. D. Billington}

Immunological Aspects of Reproduction and Fertility Control. Edited by J. P. Hearn. Pp.253. ISBN 0-85200-265-3/ 0-8391-4143-2. (MTP/University Park Press: 1980.) $£ 19.95, \$ 44.50$.

WHII.E reproductive immunology has undoubtedly come of age as a discipline in its own right, it still bears the scars of its rather uncontrolled upbringing in the hands of enthusiastic but sometimes less than rigorous investigators of a wide range of backgrounds. From the resulting morass of scattered, uneven, occasionally confusing, frequently conflicting data, it is now time to extract the relevant and scientifically sound and to reject the remainder. Reviews in this field must therefore be selective, highly critical and, most emphatically, not merely exhaustive catalogues of information. This volume of ten reviews meets this requirement only in part, with almost the full range of possibilities from the truly excellent, through the generally acceptable, to the frankly deplorable. Readers familiar with the field as a whole will hopefully readily discern these categories but the newcomer will require some guidance.

The coverage of the book is wide, with many, but not all, of the immunological aspects of reproduction and fertility control included. It is really two books in one, with the first section largely examining the maternal-foetal relationships in pregnancy and the disorders and diseases, in particular infertility and pre-eclampsia, which may result from disturbances in the normal system, and the second section exploring the possible avenues leading to the production of contraceptive vaccines based upon reproductively unique antigens. The chapters are very variable in length and approach, some presenting reviews of a general topic and others structured around more specific interests and personal data. The philosophy that an understanding of normal reproductive mechanisms will illuminate both pathological events and the means of intervention, as well as vice versa, is here given reasonable substance, and there are many encouraging signs of advance in this fascinating field.

However, this is not to say that many of the major problems do not remain to be solved. Despite considerable endeavour it is still not known by what means the foetus, or more precisely the placenta, avoids rejection as an intra-uterine allograft, whether simply by failing to display appropriate target antigens or by complex mechanisms involving one or more of a diverse range of maternal cellular and humoral immunoregulatory factors. There is conclusive cvidence for a primary immunological causation in very few clinical disorders of reproduction. An 